\title{
A system of models for the assessment of an urban distribution center in a city logistic plan
}

\author{
F. Russo, G. Musolino \& M. R. Trecozzi \\ DIIES, Dipartimento di Ingegneria dell'Informazione, \\ delle Infrastrutture e dell'Energia Sostenibile, \\ Università Mediterranea di Reggio Calabria, Italy
}

\begin{abstract}
The ex-ante assessment of the impacts generated by city logistics measures cannot be separated by the use of simulation models able to reproduce the process of distribution of final products.

The paper reports the use of urban freight demand models and proposes an aggregate simulation approach to support the ex-ante assessment of a specific distribution service connected to a nodal physical infrastructure, in particular an Urban Distribution Center (UDC).

Models have been tested in a town of southern Italy (Reggio Calabria), where a UDC has been planned. The UDC could offer a competitive service to retailers and generate positive impacts on traffic and environment, in order to balance the increasing cost of transhipment for each carrier.

Keywords: city logistics, urban freight demand models, urban distribution center.
\end{abstract}

\section{Introduction}

One of the main objectives of city logistics concerns the reduction of negative externalities generated by freight transport without depressing economic and social vitality of urban areas.

From the public utility point of view, the above objective is part of a more general goal concerning sustainability, which should 'ensure that transport systems meet society's economic, social and environmental needs, at the same time minimizing negative repercussions on the economy, society and environment' (reported in [1] as a synthesis of the international debate). 
Thus, in order to make urban mobility more sustainable, it is necessary to implement city logistics measures in order to reduce the impacts of freight transport in urban areas. A review of measures and their results is presented in [2-4]. In many cases, implemented measures have been proved ineffective, or have given contrary results to the expected ones. This was due to the fact that many of them have been implemented without an ex-ante assessment, supported by simulation models considering all the involved actors.

In order to estimate and evaluate the performance and impacts generated by urban freight measures, a key role is played by simulation models which should be able to reproduce the process of distribution of final products.

In the above context, the paper reports the use of urban freight demand models and proposes an aggregate simulation approach able to support an exante assessment of the impacts of a city logistics measure. The measure considered is a specific distribution service connected to a nodal physical infrastructure, in particular an Urban Distribution Center (UDC).

The system of models has been tested in a town of southern Italy (Reggio Calabria), where a new UDC, oriented to small and independent retailers, has been planned. The thesis is that the planned UDC could offer a competitive service to retailers and could generate positive impacts on traffic and environment.

The paper is structured into four sections. Section 2 synthetically presents the characteristics of the UDCs and the lessons learned from the review of the studies existing in literature. In Section 3 the main elements concerning the system of models for analysis of the freight distribution processes in urban areas is presented. Section 4 reports the preliminary results of the application aimed to simulate the impacts of the introduction of a UDC in terms of distances travelled and travel time. These metrics have been ex-ante estimated by comparing preand post-UDC conditions, and thus the measured improvement are related to the traffic diverted through the UDC.

\section{Review on urban distribution centers}

There is a wide range of city logistics measures that can be grouped into four categories $[1,5,6]$ :

- measure related to governance, such as delivery/pick up time windows, road pricing;

- measures on equipment, relevant to loading units (new standards) or transport units (e.g. low impact vehicles);

- measures relevant to immaterial infrastructures, such as research and education, Intelligent Transport Systems (telematics);

- measures relevant to physical infrastructures, that can be divided into linear infrastructures (i.e. roads reserved to freight vehicles only) and surface infrastructures (and/or nodal) such as loading/unloading areas, distribution centres).

An UDC is a nodal physical infrastructure, which can be defined as " $a$ facility involving the transhipment of goods directed to urban areas, aiming to 
consolidate deliveries, and thus provide greater efficiency (and effectiveness) in the distribution process by increasing the truck load factor and decreasing the number of trucks used, which help mitigate urban congestion and air pollution" (see [7]).

The presence of an UDC allows shaping a new service in the urban freight distribution process, which allows freight to be carried by means of larger vehicles outside the city and, after the transhipment, by means of smaller and less polluting vehicles inside the city.

The transhipment operation increases the costs connected to handling, ordering, inventory, damage and loss; but it could give benefits connected to the consolidation of the consignments and the optimization of freight vehicle routes and loads. Several studies on the design of optimal routes of freight vehicles in urban area are reported in [8-10].

The entity of costs and benefits connected to the UDC depends on several elements connected to [7, 11-13]:

- structure and regulations of urban transport facilities and services: size and configuration of roads, traffic conditions and regulation, pedestrian areas;

- characteristics of the UDC

o physical and organizational: size, location, store capacity, types of vehicles, presence of additional services;

o governance: degree of financial support from public institutions, presence of public in the ownership and management, characteristic of operational agreement, market areas to be covered;

- carriers freight transport operators (e.g. own account or third party, available vehicles and drivers, number of consignments in the urban area, availability of warehouses, ....) and retailers (e.g. freight received per day, store capacity, location, parking availability);

- type of freight to be delivered.

Although UDCs have been planned and implemented in several European cities (in Italy, there are the examples of Padua and Geneva), few initiatives continue to operate after some years from their implementation.

Some general lessons learned from the review of the existing studies are reported in the following. Bottom-up initiatives seem to be more successful than top-down ones because shippers, carriers and retailers are involved since the early stages of the implementation, providing their decisive contribution in the achievement and maintenance of the break-even threshold of activity level [14]. The introduction of traffic restrictions to freight transport operations, which range from time windows, to vehicle weight or speed limits, to clean vehicles, tend to favour UDCs if the restrictions are accepted by operators (e.g. by using clean vehicles, or incrementing load coefficient) or if they are fully or partly exempted from the restrictions. UDC initiatives seem to potentially work better for deliveries with a high frequency, low volume, and that contain simple products. As far as concerns logistics trips, the major potential beneficiaries of an UDC are independent and small retailers, since their deliveries are generally 
not optimized (in contrast to those of retail chains), as well as carriers making small multi-drop deliveries in areas where restrictions on delivery conditions exists (e.g. restricting regulations or congestion) (see [15]).

The above elements concerning the failures or the (potential) benefits of the planned UDCs emerged after their implementation in the different urban contexts. They are the result of a long and costly 'trial and error' approach, which emphasize the need of urban freight demand models able to simulate the effects of a planned UDC, verifying its technical compatibility and evaluating its convenience. In particular, it is necessary to finalize the research to link model system and experimental counts in terms of freight vehicles specified for typologies (capacity, refreshed,..) and for the time of day. The model system used belongs to the topological-behavioral approach that has a very large literature $[16,17]$, recently enlarged by the contemporary use of different data sources, that give the reverse problem formulation [18].

\section{Urban freight demand models}

Freight travel demand in urban area is mainly generated by two types of trips $[1,5,6]$ :

- $\quad$ shopping (attraction) trips, made by end-consumers (residents, workers) that travel from a residential (working), or consumption, zone to a purchasing zone;

- $\quad$ restocking (acquisition) trips, made by retailers, carriers, forwarders, that allow delivering the freight to the warehouses and shops, or directly to the end-consumer.

The two classes of trips may be performed by means of so-called pull or push movements (see Figure 1). In the former case, the final consumer (retailer) buys (stocks up) directly from a shop (warehouse) and he can be considered the decision-maker of the shopping (restocking) process. In the latter case, other actors choose how and from where the freight must be delivered to the final consumer (retailer), who can give some indications regarding the delivery time.

Moreover, the shopping (restocking) trip can be assumed to be a round trip if it has one residential or working zone (the shop) as origin and one shop (warehouse) as destination, or a chain trip if it has one residential or working zone (the shop) as origin and multiple shops (warehouses) as destinations.

The round (chain) trip may be open if the origin of the on-going trip is different from the destination of the coming back trip (e.g. final consumers who go out from home, make a stop in a (or more) shop(s) and reach their workplace) or closed otherwise (e.g. final consumers who go out from home, make a stop in a (or more) shop(s) and come back at home). The round (chain) trip for logistic pull movements is open if the retailer starts her/his trip from the shop, makes stop(s) in one (or more) warehouses and reach her/his own warehouse located in a different area from the shop. The round (chain) trip for logistic push movements is generally closed, because the trip starts and ends at the same point (warehouse). 


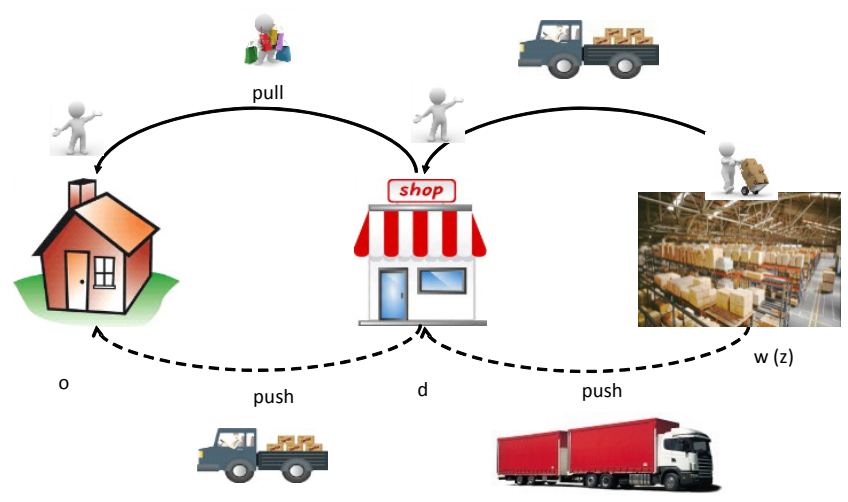

o, residence zone ; d, shopping zone; w, internal restocking zone; z, external restocking zone

Figure 1: $\quad$ Schemes of urban freight mobility (source: [1]).

The ex-ante assessment of the impacts on traffic due to the introduction of an UDC requires the specification, calibration and validation of freight demand models, which allow simulating the choices of the decision-makers involved in the urban freight transport and logistics.

The system of models used in this work consists of two levels, as shown in Figure 2.

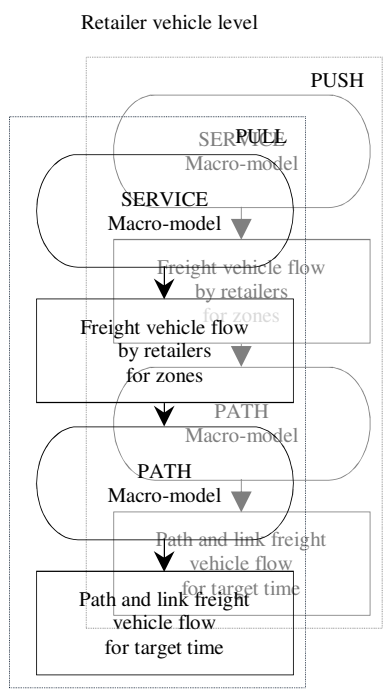

Commodity level

End consumer vehicle level
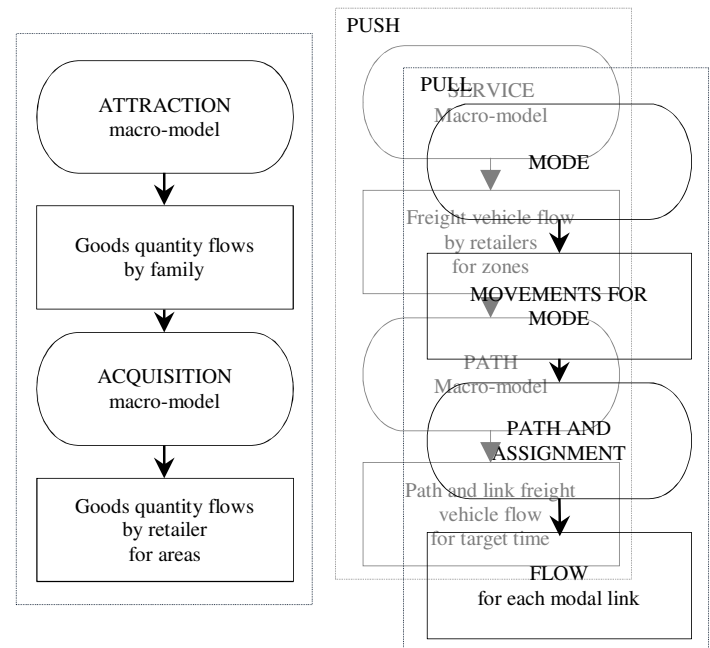

Figure 2: $\quad$ General framework of freight demand models. 
- The former is the commodity level, which simulates the attraction and acquisition movements which are the results of respectively end-consumer and retailers/carriers/ wholesalers choices. It concerns the estimation of demand flows in quantity for each freight type by $o$ - $d$ consumption pair and by $d-w$ (or $d-z)$ restocking pair.

- The latter is the vehicle level, which focuses both on the shopping (by end consumer) and restocking (by retailer) processes. It allows converting quantity flows into vehicle flows. The models concern the determination of the service, vehicle and time used as well as the path chosen for restocking sales outlets, and in similar pattern for shopping. In case of retailer the models have the same structure for movements of push and pull type; while in case of end consumer the structure of the models differ when the movement is of push type (equal to the push type of retailer) or of pull type.

\subsection{Models for commodity level}

Models for commodity level can be subdivided into:

- $\quad$ attraction macro-models, for connection between zones in which the goods are bought by the end-consumer and zones where the goods are consumed

- $\quad$ acquisition macro-models, for connection between zones where the retailers take the goods and zones where they sell them

\subsubsection{Attraction macro-models}

It is necessary, preliminary, to introduce some definitions and notations concerning:

- the identification of study area as spatial definition problem of zoning

$o$, internal zone in which the end-consumer (e.g. family) consumes (uses) the goods and the residences and services (offices) are located; in these zones the goods are consumed, or their use starts;

$d$, internal zone in which the end-consumer (e.g. family) can purchase the goods which the retailer sells; the shops are located in these zones;

$w$, internal zone to which the retailer can bring goods sold in his shop;

$z$, zone outside the study area where the end-consumer can purchase the goods which an out-retailer (or other) sells, or the (internal) retailer can bring the complementary goods sold in his/her shops.

$I_{o}$, set of zones of type 0 ;

$I_{d}$, set of zones of type d;

$I_{w}$, set of zones of type w;

$I_{z}$, set of zones of type $z$;

- the socio-economic characteristics of end consumers and the types of goods $\operatorname{pop}_{o}\left(\forall o \in I_{o}\right)$, number of residents;

$f_{o},\left(\forall o \in I_{o}\right)$, number of families;

$m_{o},\left(\forall o \in I_{o}\right)$, average number of members per family

$s$, good typology (e.g. non-perishable food) that the end consumer (e.g. family) can purchase;

$J_{s}$, set of goods typologies s. 
Assuming that the decision-maker (end consumer) is the family, the quantity of good purchased by each family is obtained as:

$$
q_{\text {sto }}=\Sigma_{j} \beta_{j s} y_{j s} \quad \forall o \in I_{o}, s \in J_{s}
$$

with

$q_{\text {sto }}$, quantity purchased of good typology $s$ by family in zone $o$ in the reference time period $t$;

$y_{j s}$, attribute j of family related to good typology s;

$\beta_{j s}$, parameter.

The total quantity of good $s$ purchased by all families living in zone $o$ in the reference time period $t, Q_{\text {sto }}$, is:

$$
Q_{\text {sto }}=\Sigma_{o} q_{\text {sto }} \quad \forall o \in I_{o}, S \in J_{S}
$$

A distribution model estimates the probability to purchase goods in a zone of the study area:

$$
p[d / o s t]=\exp \left(V_{d o}\right) / \Sigma_{d}, \exp \left(V_{d^{\prime} o}\right) \quad \forall o \in I_{o} ; d, d^{\prime} \in I_{d}
$$

where:

$p$ [d/ost], probability of purchasing good of type $s$ by family in zone $d$ conditional upon leaving from $o$ in reference time period $t$;

$V_{d\left(d^{\prime}\right) \text {, }}$ systematic utility associated to purchasing in zone $d\left(d^{\prime}\right)$.

\subsubsection{Acquisition macro-models}

The total quantity of good s acquired by retailers located in zone $\mathrm{d}$ in reference time period $t, Q_{s t d}$, is estimated as:

$$
Q_{s t d}=\Sigma_{o \in I o} p[d / o s t] Q_{s t o} \quad \forall o \in I_{o}, d \in I_{d}
$$

where the quantities $p[d / o s t]$ and $Q_{\text {sto }}$ are obtained respectively by means of eqs (2) and (3).

\subsection{Models for vehicle level}

Different classes of urban freight vehicles are used to delivery good, which differ according to loading capacity. Each class belongs to the set of Large Good Vehicles, $I_{l g v}$, characterized by a loading capacity $C^{l g v}\left(\forall \lg v \in I_{l g v}\right)$.

The number of vehicles for each $\lg v$ class is estimated as:

$$
F_{s t d}^{l g v}=Q_{s t d} / \eta^{l g v} C^{l g v}
$$

where 
$F^{l g v}$ std is the number of vehicles delivering good typology $s$ having zone $d$ as destination in time period $t$; $\eta^{\lg v}{ }_{s}$ is the loading factor of $\lg v$ vehicle delivering good typology $s$;

The target time of each restocking trip is estimated by means of a time model:

$$
p[\tau / d s t, l g v]=\operatorname{prob}\left[U_{\tau}>U_{\tau^{\prime}}\right] \quad \forall \tau \neq \tau^{\prime} ; \tau^{\prime} \in t
$$

where

$p[\tau / d s t, l g v]$ is the probability to deliver goods of type $s$ to zone $d$ by means of an $\lg v$ vehicle at time $\tau$ belonging to reference time period $t$;

$\tau$ is the desired departure/arrival time from/to zone $d$;

$U_{\tau\left(\tau^{\prime}\right)}$ is the perceived utility associated at target time $\tau\left(\tau^{\prime}\right)$.

Therefore, the flow of lgv vehicles delivering goods of typology $s$ towards zone $d$ at target time $\tau, F_{s \tau d}^{l g v}$, is estimated as:

$$
F_{s \tau d}^{l g v}=p[\tau / s t, \operatorname{lgv}, d] F_{\text {std }}^{l g v}
$$

where the quantities $F^{l g v}$ std and $p[\tau / s t, l g v, d]$ are obtained respectively by means of eqs (5) and (6).

The probability of choosing the restocking area $w$ for a retailer located in zone $d$ which acquires good of typology $s$ in time period $t, p[w / s t d]$, is estimated by means of a restocking area choice model:

$$
p[w / d s t]=\exp \left(V_{w d}\right) / \Sigma_{w^{\prime}} \exp \left(V_{w^{\prime} d}\right)
$$

where $V_{w d\left(d^{\prime}\right)}$ is the systematic utility associated to reach the restocking area $w$ conditional upon leaving from $d\left(d^{\prime}\right)$.

Finally, the flow of $\lg v$ vehicles delivering the good of typology s from zone $\mathrm{w}$ to zone $\mathrm{d}$ in reference time period $\mathrm{t}$ is obtained as:

$$
F_{s t w}^{l g v}=\Sigma_{d \in I d} p[w / s t d] F^{l g v}{ }_{s t d}
$$

where the quantities $F_{\text {std }}^{l g v}$ and $p[w / s t d]$ are obtained respectively by means of eqs (7) and (8).

\section{Application}

The proposed system of demand models has been tested in a town of southern Italy (Reggio Calabria), where a new UDC, oriented to small and independent retailers, has been planned. The thesis is that the planned UDC could offer a competitive service to these retailers and could generate positive impacts on traffic and environment, in order to balance the increasing cost of transhipment for each carrier. 
The application started with the definition of the study area, which included the municipality of Reggio Calabria (180,000 inhabitants and an extension of $236.02 \mathrm{Km}^{2}$ ). It consists of a central district with mixed residential and retail activities and clustered educational and public services; and of suburban districts with manufacturing activities and scattered residences.

The central district was the portion of the study area where the system of models has been applied (Figure 3(a)-(b)).

The application of models for the commodity level has regarded:

- the estimation of the quantities of not-perishable food purchased in independent retailers located in the central district, by means of the acquisition model;

- the estimation of the restocking process and the links between retailers and wholesalers, by means of the attraction model;

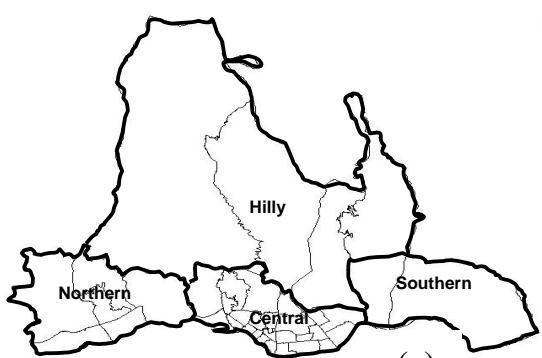

(a)

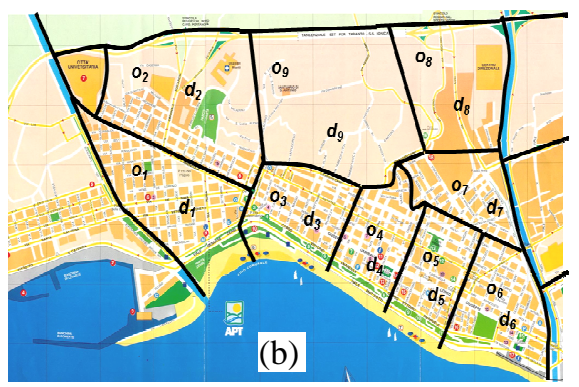

Figure 3: $\quad$ Study area (a) and portion of the central district with zones (b).

The application of models for the vehicle level has concerned the estimation of pull movements connected to the restocking trips, the path (or routes) performed during the restocking trips.

Paths of freight vehicles, performing pull movements, have been estimated by means of a stochastic path choice model, which was calibrated with data obtained from a congested network model. The link cost functions of the congested network model were calibrated with traffic counts and travel times measured on some selected links.

The following elements related to the zoning and to the types of goods were specified.

$I_{0}$ and $I_{d}$ are composed by nine zones and they are coincident: $I_{d} \equiv I_{0}$.

$I_{w}$ is composed of two zones in the current situation pre-UDC: $I_{w}=\left\{w_{1}, w_{2}\right\}$, with $\mathrm{w}_{1}$ located in southern area and $\mathrm{w}_{2}$ located in the northern area (see Figure 3.a).

$J_{S}$ is composed by the nine typologies of not-perishable food: $J_{\mathrm{s}}=\left\{\mathrm{s}_{1}, \mathrm{~s}_{2} \mathrm{~s}_{3}, \mathrm{~s}_{4}\right.$, $\left.s_{5}, s_{6}, s_{7}, s_{8}, s_{9}\right\}$, with $s_{1}=$ pasta and rice, $s_{2}=$ biscuits, $s_{3}=$ milk and cheese, $\mathrm{s}_{4}=$ eggs, $\mathrm{s}_{5}=$ oil, $\mathrm{s}_{6}=$ sugar, $\mathrm{s}_{7}=$ coffee, $\mathrm{s}_{8}=$ tea and cocoa, $\mathrm{s}_{9}=$ wine, beer and water. 


\subsection{Outcomes of freight demand models}

The application of the freight demand models allowed estimating the following quantities (see table 1):

- $Q_{w d}=\sum_{s=1 \ldots 9} Q_{s w d}$, total quantity of not-perishable food (belonging to the set of typologies $\mathrm{J}_{\mathrm{s}}$ ) acquired by retailers located in each zone $d$ of the examined area in one week ( $\mathrm{t}=$ week);

- $F^{l g v}{ }_{w d}=\Sigma_{s=1 \ldots 9} F_{s w d}^{l g v}$, number of vehicles delivering not-perishable food having zone $d$ as destination in one week ( $\mathrm{t}=$ week).

Five $\lg v$ classes of vehicles have been identified: 0, over $18000 \mathrm{~kg}$; 1, between 3600 and $18000 \mathrm{~kg}$; 2, between 1600 and $3600 \mathrm{~kg}$; 3, between 1000 and $1600 \mathrm{~kg}$; 4, up to $1000 \mathrm{~kg}$.

Table 1: $\quad$ Estimated freight quantities and vehicles delivered in the examined area.

\begin{tabular}{|c|c|c|c|c|c|c|c|}
\hline zone d & $\begin{array}{c}Q_{t d} \\
{[\mathrm{~kg} / \mathrm{w}]} \\
\end{array}$ & $\begin{array}{c}F_{\text {std }}^{0} \\
\text { [veic/w] }\end{array}$ & $\begin{array}{c}F_{\text {std }}^{1} \\
\text { [veic/w] }\end{array}$ & $\begin{array}{c}F_{\text {std }}^{2} \\
\text { [veic/w] }\end{array}$ & $\begin{array}{c}F_{\text {std }}^{3} \\
{[\text { veic/w] }}\end{array}$ & $\begin{array}{c}F_{\text {std }}^{4} \\
\text { [veic/w] }\end{array}$ & $\begin{array}{c}F_{\text {std }} \\
\text { [veic/w] }\end{array}$ \\
\hline 1 & 19875 & 0 & 0 & 1 & 3 & 8 & 13 \\
\hline 2 & 49212 & 0 & 1 & 4 & 7 & 19 & 31 \\
\hline 3 & 15756 & 0 & 0 & 1 & 2 & 6 & 10 \\
\hline 4 & 42903 & 0 & 1 & 3 & 6 & 17 & 27 \\
\hline 5 & 4928 & 0 & 0 & 0 & 1 & 2 & 3 \\
\hline 6 & 9276 & 0 & 0 & 1 & 1 & 4 & 6 \\
\hline 7 & 20238 & 0 & 0 & 2 & 3 & 8 & 13 \\
\hline 8 & 40100 & 0 & 1 & 3 & 6 & 16 & 25 \\
\hline total & 202288 & 0 & 4 & 15 & 30 & 79 & 128 \\
\hline
\end{tabular}

In order to validate the outcomes of models, freight vehicles entering in the examined area in the peak period (7:00 am - 9:00 am) of a working day have been counted and classified according to the five classes defined. The counting includes freight vehicles delivering perishable food, building materials, materials for maintenance and services and other durable goods.

Table 2: $\quad$ Counted vehicles entering in the examined area.

\begin{tabular}{cccccc}
\hline Vehicle class [lgv] & 0 & 1 & 2 & 3 & 4 \\
\hline$[$ veh/2 hours] & 13 & 126 & 123 & 120 & 246 \\
\hline$[\%]$ & 2,1 & 20,1 & 19,6 & 19,1 & 39,2 \\
\hline
\end{tabular}

\subsection{Outcomes of network model: scenarios pre and post UDC}

The effects of the planned UDC have been estimated in terms of kilometers travelled and travel times by freight vehicles during the restocking process of the retailers located in the examined area. The following traffic metrics have been specified and calculated by means of the congested road network model: 
- the minimum distance and travel time on the network between each retailerwarehouse/wholesaler origin-destination couple (pre-UDC scenario);

- the minimum distance and travel time on the network between each retailerUDC origin-destination couple (post-UDC scenario).

The assumptions on the restocking trips are the following: (i) pull movements, the decision-maker is the retailer; (ii) closed ring trips, after restocking the retailer goes back to his shop, the trip origin is the shop and the destination is the warehouse/UDC.

We considered different combinations of restocking alternatives (warehouse) for each retailer: in the pre-UDC scenario the choice set is composed by the two existing warehouses, or by one of the two ones; in the post-UDC scenario the choice set is composed by the UDC or by the warehouse with the minimum cost (related to each retailer) in the pre-UDC scenario and the UDC.

The results of the simulations are reported in Table 3, which reports the values of distance travelled and congested travel time estimated for all the retailers for the five different combinations of available alternatives connected to the two scenarios. In the combinations with more than one restocking alternative, the probability $p[w / t d]$ is estimated by means of the restocking area choice model of eq. (8).

Table 3: $\quad$ Traffic metrics estimated for the pre and post-UDC scenarios.

\begin{tabular}{cccc}
\hline \multirow{2}{*}{ Scenario } & $\begin{array}{c}\text { Available } \\
\text { alternatives }\end{array}$ & $\begin{array}{c}\text { Distance travelled } \\
{[\mathrm{km}]}\end{array}$ & $\begin{array}{c}\text { Congested travel time } \\
{[\mathrm{min}]}\end{array}$ \\
\hline \multirow{3}{*}{ Pre-UDC } & w2 & 387.2 & 738.4 \\
\cline { 2 - 4 } & $\mathrm{w} 1$ & 214.2 & 670.2 \\
\cline { 2 - 4 } & w1, w2 & 257.4 & 519.7 \\
\hline \multirow{2}{*}{ Post-UDC } & UDC & 75.0 & 342.9 \\
\cline { 2 - 4 } & w1/w2, UDC & 86.9 & 338.5 \\
\hline
\end{tabular}

\section{Acknowledgements}

This work has been partially funded by the Italian Ministry for Education, University and Research within the project PRIN2008 grant No. prot. 2008YEPPM3_002

\section{References}

[1] Russo F., Modeling behavioral aspects of urban freight movements. In: Freight Transport Modeling, M. Ben-Akiva, H. Meersman \& E. Van de Voorde (eds), Emerald Group Publishing Limited, 2013. ISBN 978-1-7819285-1. 
[2] COST 321, Urban goods transport - final report of the action. Belgium: Transport Research, European Commission Directorate General Transport, 1998.

[3] City Ports, City ports e project interim report. Emilia-Romagna Region, Bologna, Italy, 2005.

[4] BESTUFS, BESTUFS - good practice guide on urban freight. BESTUFS Consortium. www.bestufs.net, 2007.

[5] Russo, F. \& Comi, A., A modelling system to simulate goods movements at an urban scale. Transportation, 37 (6), pp. 987-1009, 2010.

[6] Russo, F. \& Comi, A., Measures for sustainable freight transportation at urban scale: Expected goals and tested results in Europe. Journal of Urban Planning and Development, 137 (2), pp. 142-152, 2011.

[7] Tario J. D. et al., Urban distribution centers: a means to reducing freight vehicle miles travelled. Final Report. Prepared for the New York State Energy Research and Development Authority. Albany, NY, 2011.

[8] Polimeni A., Russo F. \& Vitetta A., Demand and routing models for urban goods movement simulation. European Transport-Trasporti Europei, 46, pp. 3-23, 2010.

[9] Russo F., Vitetta A. \& Polimeni A., From single path to Vehicle Routing: the retailer delivery approach. Procedia - Social and Behavioral Sciences, 2 (3), pp. 6378-6386, 2010.

[10] Polimeni A. \& Vitetta A., Optimising waiting at nodes in time-dependent networks: cost functions and applications. Journal of Optimization Theory and Applications, 156(3), pp. 805-818, 2013.

[11] Taniguchi, E., Noritake, M., Yamada, T. \& Izumitani, T. Optimal size and location planning of public logistics terminals, Transportation Research Part E 35, Elsevier Science, U.S.A. 1999.

[12] BESTUFS II, Quantification of Urban Freight Transport Effects II. BESTUFS II Deliverable 5.2 available at http://www.bestufs.net/ (accessed on 20 July 2012), 2008.

[13] Danielis R. \& Marcucci, E., The potential demand for an urban freight consolidation centre. Transportation, 35. pp. 269-284, 2008

[14] Quak, H., Sustainability of urban freight transport. Retail distribution and local regulations in cities. Erasmus University, Rotterdam, 2008

[15] Browne, M., Sweet, M., Woodburn, A. \& Allen, J., Urban Freight Consolidation Centres. Final Report. Department of Transport, UK, 2005

[16] Cascetta, E., Transportation Systems Analysis. Models and Applications. Springer-Verlag, New York, 2008.

[17] Russo F. \& Musolino G. A unifying modelling framework to simulate the Spatial Economic Transport Interaction process at urban and national scales. Journal of Transport Geography, 24, pp. 189-197, 2012.

[18] Russo, F. \& Vitetta, A., Reverse assignment: calibrating link cost functions and updating demand from traffic counts and time measurements. Inverse Problems in Science and Engineering, 19 (7), 921-950, 2011. 